\title{
Vehicle Routing Problem with Simultaneous Pickup and Delivery in Cross-Docking Environment
}

\author{
Chikong Huang and Yun-Xi Liu
}

\begin{abstract}
This study will discuss the vehicle routing problem with simultaneous pickup and delivery in a cross-docking environment. The transportation system includes three stages: (1) pickup goods, (2) delivery goods and pickup returned goods, and (3) delivery all returned goods. In the second stage, some operations of stage (3) may be accepted if time and loading capacity are available. We believe this special design can further reduce the transportation cost. A mathematical model is developed. The objective of this model is to minimize overall transportation cost including the vehicle transportation cost and the fixed cost of each route. An appropriate heuristic algorithm for solving the problem is also developed by using Tabu logic. Result of numerical example indicates that the proposed three-stage transportation system and heuristic algorithm can solve the vehicle routing problem effectively and efficiently.
\end{abstract}

Index Terms-Cross-docking, pickup and delivery, vehicle routing problem.

\section{INTRODUCTION}

In the extremely competitive and rapidly changing market, improving the efficiency of logistics system can not only reduce operation cost for enterprises but also improve customer satisfaction. A traditional transportation system can either deliver goods or pickup goods through vehicle routings. However, simultaneous pickup and delivery within single operation becomes a new trend in Taiwan. In addition, the cross-docking concept has been introduced to logistic system. This approach can effectively reduce the cost of warehouse facilities and increase operation efficiency. It is believed that a cross-docking system combined with simultaneous pickup and delivery operations will be a new idea for design of logistic system.

This study proposes a new concept of transportation system assuming simultaneous pickup and delivery operations in a cross-docking environment. Within a planning period, this transportation system aggregates all delivery and pickup operations in three consecutive transportation stages. In the first stage, all goods are picked up from the suppliers to the cross-docking area by several independent vehicle routings. The second transportation stage, all goods are delivered to the end customers. Simultaneously, this stage performs pickup operations for all returned goods from the end customers if they call for. All vehicles in this stage depart from the cross-docking area and

\footnotetext{
Manuscript received August 25, 2013; revised November 6, 2013. Thi work was supported in part by the National Science Counsel, Taiwan ROC under Grant NSC 102-2221-E-224-030.

Chikong Huang and Yun-Xi Liu are with the National Yunlin University of Science and Technology, Yunlin 640, Taiwan (e-mail: huangck@yuntech.edu.tw,m10021037@yuntech.edu.tw).
}

come back to the same area gathering all returned goods. After sorting the returned goods at the cross-docking area, the third transportation stage starts at the same time. In this stage, all returned goods will be delivered back to the suppliers through several independent vehicle routes.

One special design in the second stage is that we accept some vehicles to deliver the returned goods to their final destinations if time and loading capacity are permitted. We believe this optional task, which originally should be executed in the third transportation stage, can further reduce the overall transportation cost.

The three-stage transportation system in this research makes the solution process more difficult. However, if the overall cost can be further reduced, it is still worth to do. Based on this idea, a mathematical model will be developed in section III and a solution algorithm is also proposed in section IV.

\section{LITERATURE REVIEW}

\section{A. Cross-Docking Transportation}

The cross-docking transportation is one strategy of warehouse design. Goods can stay in cross-docking area for sorting and re-loading vehicle in a short period of time. Goods will be delivered to next destination by another fleet which usually departs the cross-docking area at the same tome. Due to the short time storage and minimum storage facilities required, it is believed that the cross-docking design can effectively reduce transportation cost and minimize inventory cost [1]. Reference [2] indicates that this approach can also increase customer satisfaction, reduce operating time, and reduce lead time of delivery.

In the real-world application of cross-docking design, both Wal-Mart and Toyota show benefits on cost-effective. Timing is an important design factor, especially for vehicle pickup and delivery system [3]. This paper will try to take these advantages in developing a new vehicle transportation system.

\section{B. Vehicle Routing Problems}

The vehicle routing problem (VRP) is first discussed by Dantzing \& Ramser [4] on the truck dispatching problem (TDP). Traditional VRP is focused on dispatching fleet on execution the delivery service given a single depot, service nodes and quantities required. The objective is to minimize travel distance or delivery cost. In the recent years, several real-world constraints have been considered to a traditional vehicle routing problem, such as the capacitated VRP, the multi-depot VRP, the VRP with time windows, the pick-up and delivery VRP. These additional conditions make the problem more realistic but more difficult to solve. 
Since the cross-docking operations will connect two consecutive deliveries, therefore, the VRP with hard time windows will applies in this research. In addition, a fixed and given loading capacity for each vehicle and simultaneous pickup and delivery operations in the second stage are all necessary assumptions.

\section{Heuristic Algorithms}

In the recent years, several meta-heuristic algorithms have been well developed for solving the NP-hard vehicle routing problems, such as Simulated Annealing algorithms [5], Tabu Searches, Genetic Algorithms [6]. For effectively use of each meta-heuristic, a set of design parameters should be tested and fine-tuned. This study will apply the logic of Tabu search. The design parameters include length of Tabu list, number of iterations, and probabilities of neighborhood searching approaches. The Taguchi approach will be used in this study to decide suitable design parameters for Tabu search.

\section{Problem Assumptions AND Model Construction}

\section{A. Problem Statement and Assumptions}

The proposed three-stage transportation system will be modeled in this section and it will also be described in details. Operations in one transportation stage are independent to the operations in other stages. All transportation operations should be ended within a given planning period or working period.

The first transportation stage performs all pickup operations from the suppliers. In this stage, all vehicles depart the cross-docking area at the same time and they will return to the cross-docking area within a given time window. After sorting and arranging goods at the cross-docking area, the second stage can be started.

The second transportation stage executes two tasks for end customers: (1) goods delivery to end customers and (2) pickup returned goods from end customers. In this stage, all vehicles depart the cross-docking area at the same time and they will return to the cross-docking area within a given time window. After sorting and arranging the returned goods at the cross-docking area, the third transportation stage can be started.

The third transportation stage delivers all returned goods back to the suppliers or return points. All vehicles in the third stage depart the cross-docking area at the same time and they should return to the cross-docking area before the end of planning period, i.e. the end of working period.

Because the single cross-docking area plays an important role for goods sorting, vehicle dispatching, and vehicle re-loading. Therefore, a hard time window is absolutely necessary especially for the time period between the $1^{\text {st }}$ and $2^{\text {nd }}$ stages and the time period between the $2^{\text {nd }}$ and $3^{\text {rd }}$ stages. Several assumptions and limitations should be clearly defined before the model construction.

The basic assumptions applied for all three stages are listed as follows.

- There is a single cross-docking area, location is fixed, given, and known.

- Location and quantity for each supplier and end customer are fixed, given, and known.

- In each stage, each node can be served by one vehicle and be served once only.

- Only one vehicle type, loading capacity and vehicle speed are fixed, given, and known.

- Transportation cost per unit distance and fixed cost per rout are fixed, given, and known.

- Delivery quantity for each node should be less than the vehicle loading capacity.

- No inventory and no defect item occur in all stages. All goods and returned goods are balanced in the system.

- Time for goods sorting, vehicle dispatching, and vehicle re-loading at the cross-docking area is fixed, given, and known. No inventory cost is considered in this study.

- All operations should be finished within the planning period.

- Shipping quantities of the planning period should meet the quantities required by end customers.

The basic assumptions for the first transportation stage are listed as follows:

1) Only pickup operations are executed in this stage.

2) All vehicles depart from the cross-docking area at the same time with empty loading.

3) All vehicles return to the cross-docking area within a given time window.

The basic assumptions for the second transportation stage are listed as follows:

1) Assume three types of delivery requirement for the end customer: (1) delivery goods only, (2) returned goods only, (3) both delivery goods and returned goods at the same time.

2) Vehicle can send the returned goods directly to the final destinations, i.e. suppliers, if the time and loading capacity are tolerable.

3) All vehicles depart from the cross-docking area at the same time which is estimated by the latest vehicle return time in the first stage plus the fixed sorting time spent in the cross-docking area.

4) All vehicles should return to the cross-docking area within a given time window.

The basic assumptions for the third transportation stage are listed as follows.

1) Only the returned goods will be served in this stage.

2) All vehicles depart from the cross-docking area at the same time which is calculated by the latest vehicle return time in the second stage plus the fixed sorting time spent in the cross-docking area.

3) All empty vehicles should return to the cross-docking area before the end of planning period.

\section{B. Definitions of Variables and Notations}

The following definition for notations, sets, parameters, and decision variables will be used in the mathematical model.

\section{- Notations:}

$i, j, h$ : Index for suppliers, end customers, and return points

(i.e. suppliers)

$k$ : Index for vehicles

- Sets:

$N$ : The set of all nodes which include suppliers $(n)$, end customers $(m)$, and return points $(n)$

$N_{0}$ : The set of all nodes including cross-docking point

$p$ : The set of all suppliers, $p=\{1,2, \ldots, n\}$ 
$P$ : The set of all suppliers including cross-docking point, $P=\{0,1,2, \ldots, n\}$

$d$ : The set of all end customers,

$d=\{n+1, n+2, \ldots, n+m\}$

$D$ :The set of all end customers including cross-docking point, $D=\{0, n+1, n+2, \ldots, n+m\}$

$z$ : The set of all return points, $z=p$

$Z$ : The set of all return points including cross-docking point, $Z=P$

$K$ :The set of all vehicles

- Parameters:

$C$ :Transportation cost per unit distance

$F C$ : Fixed cost per route

$Q$ :Loading capacity of vehicle

$D q 1_{0}^{k}$ : In the $1^{\text {st }}$ stage, loading quantity of vehicle $k$ when it departs from cross-docking point

$D q 1_{i}^{k}$ : In the $1^{\text {st }}$ stage, loading quantity of vehicle $k$ when it departs from node $i$

$D q 2_{0}^{k}$ : In the $2^{\text {nd }}$ stage, loading quantity of vehicle $k$ when it departs from cross-docking point

$D q 2_{i}^{k}$ : In the $2^{\text {nd }}$ stage, loading quantity of vehicle $k$ when it departs from node $i$

$D q 3_{0}^{k}$ : In the $3^{\text {rd }}$ stage, loading quantity of vehicle $k$ when it departs from cross-docking point

$D q 3_{i}^{k}$ : In the $3^{\text {rd }}$ stage, loading quantity of vehicle $k$ when it departs from node $i$

$p_{i}$ : Pickup quantity at supplier $i$

$d_{i}$ : Delivery quantity at end customer $i$

$d p_{i}$ : Pickup quantity for returned goods at end customer $i$ $z_{i}$ : Quantity of returned goods at return point (supplier) $i$ $d_{i j}$ : Distance from node $i$ to node $j$

$S P$ : Vehicle speed

$C_{i j}$ : Transportation cost from node $i$ to node $j, C_{i j}=C *$ $d_{i j}$

$e t_{i j}:$ Vehicle travel time from node $i$ to node $j, e t_{i j}=\frac{d_{i j}}{S P}$

$U P 1$ : After end of $1^{\text {st }}$ stage, time for sorting and reloading vehicle at cross-docking point

$U P 2$ : After end of $2^{\text {nd }}$ stage, time for sorting and reloading vehicle at cross-docking point

$s_{i}$ : Service time at node $i$

$D T 1_{i}^{k}$ : In the $1^{\text {st }}$ stage, departure time of vehicle $k$ at node $i$

$A T 1_{i}^{k}$ : In the $1^{\text {st }}$ stage, arrival time of vehicle $k$ at node $i$

$D T 2_{i}^{k}$ : In the $2^{\text {nd }}$ stage, departure time of vehicle $k$ at node $i$

$A T 2_{i}^{k}$ : In the $2^{\text {nd }}$ stage, arrival time of vehicle $k$ at node $i$

$D T 3_{i}^{k}$ : In the $3^{\text {rd }}$ stage, departure time of vehicle $k$ at node $i$

$A T 3_{i}^{k}$ : In the $3^{\text {rd }}$ stage, arrival time of vehicle $k$ at node $i$

$A T P_{\text {max }}$ : In the $1^{\text {st }}$ stage, the latest vehicle returning time at cross-docking point

$A T D_{\text {max }}$ : In the $2^{\text {nd }}$ stage, the latest vehicle returning time at cross-docking point

$D D T$ : In the $2^{\text {nd }}$ stage, departure time for all vehicles at cross-docking point, $D D T=A T P_{\max }+U P 1$

$Z D T$ : In the $3^{\text {rd }}$ stage, departure time for all vehicles at cross-docking point, $Z D T=A T D_{\max }+U P 2$

$T_{p}$ : Service time (upper limit) for the $1^{\text {st }}$ stage

$T_{d}$ : Service time (upper limit) for the $1^{\text {st }}$ stage plus the $2^{\text {nd }}$ stage

$T$ : Service time (upper limit) for all three stages, time for one planning period
M: a maximal positive number

Decision variables:

$X_{i j}^{k}:\left\{\begin{array}{c}1, \text { If vehicle } k \text { serve the path between node } i \text { and } \\ \text { node } j \text { in the first stage } \\ 0, \text { Otherwise }\end{array}\right.$

$Y_{i j}^{k}:\left\{\begin{array}{l}1, \text { If vehicle } k \text { serve the path between node } i \text { and } \\ \text { node } j \text { in the second stage } \\ 0, \text { Otherwise }\end{array}\right.$

$Z_{i j}^{k}:\left\{\begin{array}{l}1, \text { If vehicle } k \text { serve the path between node } i \text { and } \\ \text { node } j \text { in the third stage } \\ 0, \text { Otherwise }\end{array}\right.$

$U_{i}^{k}:\left\{\begin{array}{l}1, \text { If vehcle } k \text { serve node } i \text { in the first stage } \\ 0, \text { Otherwise }\end{array}\right.$

$V_{i}^{k}:\left\{\begin{array}{l}1, \text { If vehcle } k \text { serve node } i \text { in the second stage } \\ 0, \text { Otherwise }\end{array}\right.$

$B_{i}^{k}:\left\{\begin{array}{l}1, \text { If vehcle } k \text { serve node } i \text { in the third stage } \\ 0, \text { Otherwise }\end{array}\right.$

\section{Model Construction}

The mathematical model in this section integrates three transportation stages and it becomes a complicate and large-scale vehicle routing problem.

Minimize $Z=$

$$
\begin{gathered}
\sum_{i \in P} \sum_{j \in P} \sum_{k \in K} C_{i j} X_{i j}^{k}+\sum_{i \in N_{0}} \sum_{j \in N_{0}} \sum_{k \in K} C_{i j} Y_{i j}^{k}+ \\
\sum_{i \in Z} \sum_{j \in Z} \sum_{k \in K} C_{i j} Z_{i j}^{k}+\sum_{j \in p} \sum_{k \in K}(F C) X_{0 j}^{k}+ \\
\sum_{j \in N} \sum_{k \in K}(F C) Y_{0 j}^{k}+\sum_{j \in Z} \sum_{k \in K}(F C) Z_{0 j}^{k}
\end{gathered}
$$

Subject to:

$$
\begin{array}{cc}
\sum_{i \in P} \sum_{k \in K} X_{i j}^{k}=1 & j=1, \ldots, n \\
\sum_{j \in P} \sum_{k \in K} X_{i j}^{k}=1 & i=1, \ldots, n \\
\sum_{i \in N} \sum_{k \in K} Y_{i j}^{k}=1 & j=1, \ldots, n \\
\sum_{j \in N} \sum_{k \in K} Y_{i j}^{k}=1 & i=1, \ldots, n \\
\sum_{i \in Z} \sum_{k \in K} Z_{i j}^{k} \leq 1 & j=1, \ldots, n \\
\sum_{j \in Z} \sum_{k \in K} Z_{i j}^{k} \leq 1 & i=1, \ldots, n \\
\sum_{i \in P} X_{i j}^{k}-\sum_{i \in P} X_{j i}^{k}=0 & j \in P \quad k \in K \quad i \neq j \\
\sum_{i \in N_{0}} Y_{i j}^{k}-\sum_{i \in N_{0}} Y_{j i}^{k}=0 & j \in N \quad k \in K \quad i \neq j \\
\sum_{i \in Z} Z_{i j}^{k}-\sum_{i \in Z} Z_{j i}^{k}=0 & j \in Z \quad k \in K \quad i \neq j \\
\sum_{j \in p} X_{o j}^{k}=1 & k \in K \\
\sum_{i \in p} X_{i o}^{k}=1 & k \in K \\
\sum_{j \in d} Y_{o j}^{k}=1 & k \in K \\
\sum_{i \in N} Y_{i o}^{k}=1 & k \in K \\
\sum_{j \in Z} Z_{o j}^{k} \leq 1 & k \in K \\
\sum_{i \in Z} Z_{i o}^{k} \leq 1 & k \in K \\
D q 1_{0}^{k}=0 & k
\end{array}
$$




$$
\begin{aligned}
& D q 2_{j} \geq D q 2_{0}^{k}-d_{j}+d p_{j}-\left(1-Y_{0 j}^{k}\right) \times M j \epsilon N, k \in K(21) \\
& D q 2_{j} \geq D q 2_{i}-d_{j}+d p_{j}-z_{j}-\left(1-Y_{i j}^{k}\right) \times M \\
& i, j \in N, k \in K \\
& D q 3_{0}^{k}=\sum_{i \in Z} \sum_{j \in Z} Z_{j} \times Z_{i j}^{k} \quad k \in K \\
& D q 3_{j} \geq D q 3_{0}^{k}-z_{j}-\left(1-Z_{0 j}^{k}\right) \times M \quad j \in Z \quad k \in K \\
& D q 3_{j} \geq D q 3_{i}-z_{j}-\left(1-Z_{i j}^{k}\right) \times M i, j \in z \quad k \in K \\
& D q 1_{0}^{k} \leq Q \quad k \in K \\
& D q 2_{0}^{k} \leq Q \quad k \in K \\
& D q 3_{0}^{k} \leq Q \quad k \in K \\
& D q 3_{j} \leq Q+\left(1-\sum_{i \in p} Z_{i j}^{k}\right) \times M \quad j \in p \quad k \in K \\
& \sum_{i \in P} p_{i} * U_{i}^{k}=\sum_{i \in D} d_{i} \times V_{i}^{k} \quad k \in K \\
& \sum_{i \in D} d p_{i} * V_{i}^{k}=\sum_{i \in P} z_{i} *\left(V_{i}^{k}+B_{i}^{k}\right) \quad k \in K \\
& \sum_{i \in P} \sum_{j \in P} \sum_{k \in K} s_{i} X_{i j}^{k}+\sum_{i \in P} \sum_{j \in P} \sum_{k \in K} e_{i j} X_{i j}^{k} \leq T_{p} \\
& \sum_{i \in P} \sum_{j \in P} \sum_{k \in K} s_{i} X_{i j}^{k}+\sum_{i \in P} \sum_{j \in P} \sum_{k \in K} e t_{i j} X_{i j}^{k}+ \\
& \sum_{i \in D} \sum_{j \in N} \sum_{k \in K} s_{i} Y_{i j}^{k}+\sum_{i \in D} \sum_{j \in N} \sum_{k \in K} e t_{i j} Y_{i j}^{k} \leq T_{d} \\
& \sum_{i \in P} \sum_{j \in P} \sum_{k \in K} s_{i} X_{i j}^{k}+\sum_{i \in P} \sum_{j \in P} \sum_{k \in K} e t_{i j} X_{i j}^{k}+ \\
& \sum_{i \in D} \sum_{j \in N} \sum_{k \in K} s_{i} Y_{i j}^{k}+\sum_{i \in P} \sum_{j \in P} \sum_{k \in K} e t_{i j} Y_{i j}^{k}+ \\
& \sum_{i \in P} \sum_{j \in P} \sum_{k \in K} s_{i} Z_{i j}^{k}+\sum_{i \in P} \sum_{j \in P} \sum_{k \in K} e t_{i j} Z_{i j}^{k} \leq T \\
& \begin{array}{c}
D T 1_{j}^{k} \geq e t_{i j}+D T_{i}^{k}+s_{j}-\left(1-X_{i j}^{k}\right) \times M \\
i, j \in P \quad k \in K
\end{array} \\
& D T 2_{j}^{k} \geq e t_{i j}+D T_{i}^{k}+s_{j}-\left(1-Y_{i j}^{k}\right) \times M \\
& i, j \in N_{0} \quad k \in K \\
& D T 3_{j}^{k} \geq e t_{i j}+D T_{i}^{k}+s_{j}-\left(1-Z_{i j}^{k}\right) \times M \\
& i, j \in Z \quad k \in K
\end{aligned}
$$

$$
\begin{gathered}
A T 1_{j}^{k} \geq e t_{i j}+D T_{i}^{k}-\left(1-X_{i j}^{k}\right) \times M \quad i, j \in P \quad k \in K \\
A T 2_{j}^{k} \geq e t_{i j}+D T_{i}^{k}-\left(1-Y_{i j}^{k}\right) \times M \quad i, j \in N_{0} k \in K \\
A T 3_{j}^{k} \geq e t_{i j}+D T_{i}^{k}-\left(1-Z_{i j}^{k}\right) \times M \quad i, j \in Z \quad k \in K \\
A T 1_{\max }=\operatorname{Max}\left\{A T 1_{0}^{k} X_{i 0}^{k} \quad i \in P \quad k \in K\right\} \\
A T 2_{\max }=\operatorname{Max}\left\{A T 2_{0}^{k} Y_{i 0}^{k} \quad i \in N_{0} \quad k \in K\right\} \\
D D T \geq A T 1_{\max }+U P 1-\left(1-\sum_{k \in K} X_{i 0}^{k}\right) \times M
\end{gathered}
$$$$
M i \in P \quad k \in K
$$

$$
\begin{gathered}
Z D T \geq A T 2_{\max }+U P 2-\left(1-\sum_{k \in K} Y_{i 0}^{k}\right) \times M \\
i \in N \quad k \in K \\
\sum_{j \in P} X_{i j}^{k}=U_{i}^{k} \quad i \in p \quad i \neq j \quad k \in K \\
\sum_{j \in N_{0}} Y_{i j}^{k}=V_{i}^{k} \quad i \in N \quad i \neq j \quad k \in K \\
\sum_{j \in Z} Z_{i j}^{k}=B_{i}^{k} \quad i \in z \quad i \neq j \quad k \in K \\
\sum_{k \in K} U_{i}^{k}=1 \quad i \in p
\end{gathered}
$$

$$
\begin{array}{cc}
\sum_{k \in K} V_{i}^{k}=1 & i \in d \\
\sum_{k \in K} V_{i}^{k}+\sum_{k \in K} B_{i}^{k}=1 & i \in Z \\
X_{i j}^{k} \in\{0,1\} \quad i, j \in P & k \in K \\
Y_{i j}^{k} \in\{0,1\} \quad i, j \in N_{0} & k \in K \\
Z_{i j}^{k} \in\{0,1\} & i, j \in Z \quad k \in K \\
U_{i}^{k} \in\{0,1\} & i \in P \quad k \in K \\
V_{i}^{k} \in\{0,1\} \quad i \in N_{0} & k \in K \\
B_{i}^{k} \in\{0,1\} & i \in Z \quad k \in K
\end{array}
$$

The objective function in equation (1) is to minimize overall cost, which include transportation costs in three stages and fixed costs of vehicle routing in three stages. Equation (2) to (7) makes sure that each node in each stage is served once by one vehicle. Equation (8) to (10) indicates a balanced flow quantity in each stage. Equation (11) to (16) confirms that each route starts from the cross-docking point.

Vehicle loading constraints and limitations are described from equation (17) to (31). Equation (17) makes sure the vehicle in the $1^{\text {st }}$ stage should be empty when departing from the cross-docking point. For each transportation stage, equation (18)-(19), (20)-(22), and (23)-(25) show the variation of loading quantity between two successive nodes in a route. Equation (26) to (31) confirms that no overloading is acceptable.

Equation (32) makes sure that total pickup quantity in the $1^{\text {st }}$ stage equals to total delivery quantity in the $2^{\text {nd }}$ stage. For the returned goods, equation (33) indicates the pickup quantity is the same as the delivery quantity.

The constraints of operation time and time fence are described from equation (34) to (46). Equation (34) to (36) indicates that all operations in each stage should be finished within time window. Equation (37) to (42) shows how to accumulate departure time and arrival time between two successive nodes. Equation (43) to (44) defines the latest returning time for the $1^{\text {st }}$ stage and the $2^{\text {nd }}$ stage. Equation (45) to (46) defines the departure time for the $2^{\text {nd }}$ stage and the $3^{\text {rd }}$ stage.

Equation (47) to (49) defines the relationship between two decision variables. Equation (50) makes sure that each supplier should be served by one vehicle only. Equation (51) makes sure that each end customer should be served by one vehicle only. Equation (52) makes sure that each return point should be served by one vehicle only either in the $2^{\text {nd }}$ stage or in the $3^{\text {rd }}$ stage. Finally, equation (53) to $(58)$ forces the decision variables to be an integer, either 0 or 1 .

\section{CONCEPT OF SOlution Algorithm}

A heuristic solution algorithm on the basis of Tabu logic is developed for finding all three-stage vehicle routings in details. The output of this solution algorithm should answer the following questions for management level: how many routes required in each stage, how many vehicle is necessary to execute all operations in the planning period, the detailed vehicle travel plan for each individual routing. The most important information is the overall cost of this transportation system, which includes the delivery costs and the fixed costs 
of all routes in each transportation stage. The overall design logic of this proposed solution algorithm is presented in Fig. 1 .

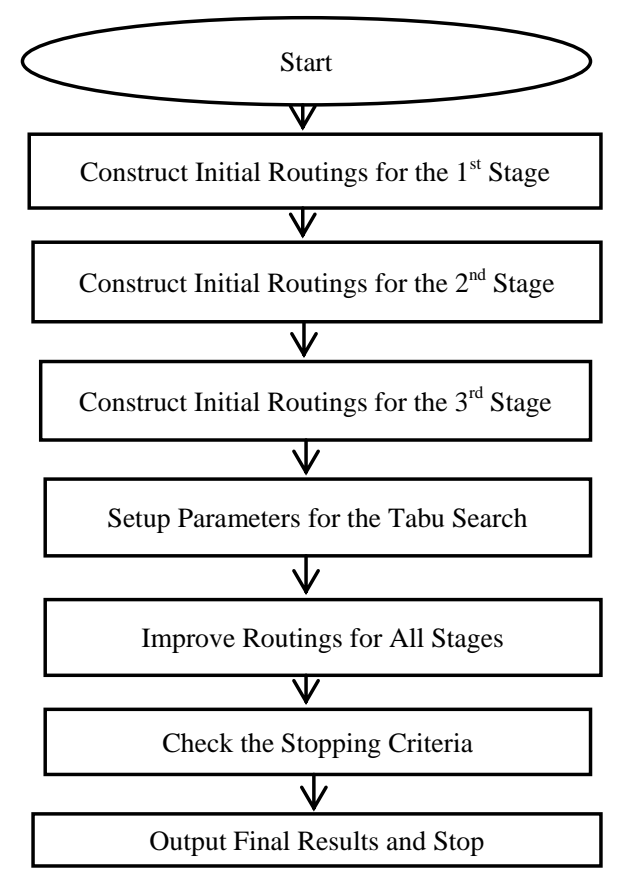

Fig. 1. Design logic for the solution algorithm.

There are two phases in the design logic. The first phase is to construct initial vehicle routings starting from the $1^{\text {st }}$ transportation stage to the $3^{\text {rd }}$ transportation stage in sequence. The basic idea for constructing an initial routing is using the neighborhood searching approach starting from the depot point, i.e. the cross-docking point in this research. Once a nearest new service node is found, several checking criteria should be considered, such as the accumulated loading quantity, the accumulated service time, time left to return to the depot point. In each transportation stage, these iterations will be repeatedly executed until all service points are arranged in a routing plan.

The second phase of the design logic is to improve the initial vehicle routings in the system. This phase applies the Tabu logic for routing improvement and integrates all three transportation stages in one improving process. The design parameters of this Tabu search include the length of Tabu list, number of iteration to end the searching process, probabilities for selection of neighborhood exchange approaches. There are four possible neighborhood exchange approaches developed in each transportation stage. For the first transportation stage, the improvement approaches include: (1) external route 1-0 node change, (2) external route 1-1 node exchange, (3) internal route 2 -opt node exchange, and (4) internal route or-opt node exchange. The improvement approaches for the second and third stage are: (1) external route 1-0 node change, (2) external route 2 -exchange, (3) internal route 2 -opt node exchange, and (4) internal route or-opt node exchange.

In addition, the Taguchi experiment approach is used for fine tuning the design parameters of Tabu search. For solving the real-world and large-scale problem, the solution algorithm developed in this research is further coded by the VBA language and running on Windows 7 system.

\section{DEMONSTRATION EXAMPLE AND DisCUSSION}

\section{A. Basic Data of the Illustration Example}

A numerical example with one cross-docking point is developed in this section to demonstrate effectiveness of the mathematical model and the efficiency of the solution algorithm proposed in this study. In this example, there are 50 nodes within a square area, i.e. 100 by 100 kilometer. 20 nodes out of 50 are suppliers which also recognized as the return points. The rest of them are the end customers. Fig. 2 indicates all locations including: the cross-docking point (yellow square), all suppliers (blue triangles), and all end customers (red circles). Delivery quantities are generated by a uniform distribution between 10 and 50. Quantities of returned goods are also uniformly distributed between 0 and 20 .

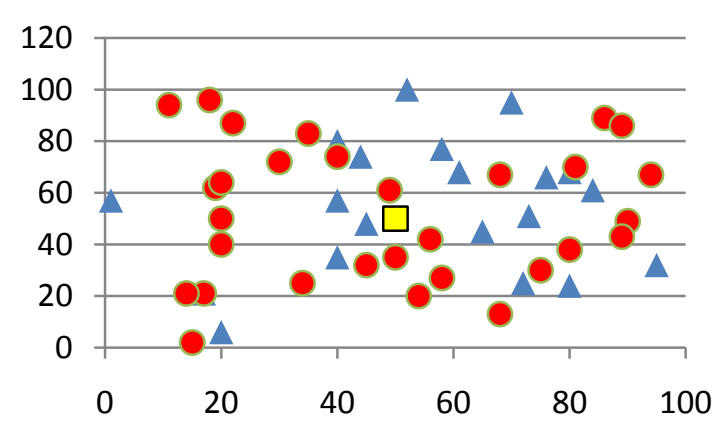

Fig. 2. Locations of cross-docking point and 50 nodes.

The loading capacity of each vehicle is 150 units and the average vehicle speed is 60 kilometer per hour. The fixed cost for each vehicle route is $\$ 500$. Service time at each supplier or end customer is 0.1 minute per unit.

The operation time for all three transportation stages is 480 minutes which is also recognized as one planning period. The time period for the first stage operation is 160 minutes. After sorting goods and reloading truck, all vehicles should leave the cross-docking area and start the second transportation stage. The operation time for the second stage is 200 minutes and it is followed by the time for goods sorting and truck reloading. All operations should be ended by 480 minutes.

\section{B. Design Parameters of Tabu Search}

When the solution program and basic data of example are ready, a Taguchi experiment is conducted to set up appropriate design parameters for Tabu search. As indicated in section IV, the design parameters include: length of Tabu list, maximal iteration number, and probabilities for selecting improvement approaches. Since each parameter is defined in three levels, the $\mathrm{L}_{9}$ orthogonal table is suitable in this case. The final results of Taguchi experiment are summarized in Table I and Table II for all three stages.

TABLE I: THE DESIGN PARAMETERS FOR THE FIRST STAGE

\begin{tabular}{|l|l|l|l|}
\hline \hline Parameter & Level & Values & Remarks \\
\hline $\begin{array}{l}\text { Length of Tabu } \\
\text { list }\end{array}$ & 2 & 7 & - \\
\hline $\begin{array}{l}\text { Maximal iteration } \\
\text { number }\end{array}$ & 3 & 150 & - \\
\hline $\begin{array}{l}\text { Probabilities for } \\
\text { improvement } \\
\text { approaches }\end{array}$ & 3 & $2 / 6$ & External 1-0 change \\
& & $1 / 6$ & $\begin{array}{l}\text { Internal 1-1 exchange } \\
\text { Internal or-opt exchange }\end{array}$ \\
\hline \hline
\end{tabular}


TABLE II: THE DESIGN PARAMETERS FOR THE SECOND AND THIRD STAGE

\begin{tabular}{|l|l|l|l|}
\hline \hline Parameter & Level & Values & Remarks \\
\hline $\begin{array}{l}\text { Length of Tabu } \\
\text { list }\end{array}$ & 2 & 7 & - \\
\hline $\begin{array}{l}\text { Maximal iteration } \\
\text { number }\end{array}$ & 3 & 150 & - \\
\hline $\begin{array}{l}\text { Probabilities for } \\
\text { improvement } \\
\text { approaches }\end{array}$ & 2 & $1 / 6$ & $\begin{array}{l}\text { External 1-0 change } \\
\text { External 2-exchange }\end{array}$ \\
\hline \hline
\end{tabular}

\section{Solution of the Example and Discussion}

Based on the solution algorithm described in section IV, a computer program is then developed to solve this numerical example. For demonstration and comparison purpose, Table III and Table IV show the initial solution and the final solution, respectively. Table $\mathrm{V}$ compares the initial and final solutions on the basis of total cost, travel times, and number of routings used in each stage. Fig. 3 shows the final vehicle routings for all stages in details.

By comparing the initial solution and the final solution, the total cost can be reduced $14.69 \%$ and the number of routing can be effectively reduced up to $20 \%$. Reduction of routings, i.e. 3 routing in this example, may represent a better utilization of vehicle and fully utilizing the time of panning period. These results indicate that the proposed solution algorithm can effectively reduce the cost and increase the efficiency of the transportation system.

There are 135 returned goods should be delivered back to suppliers starting from end customers. Data from the initial solution indicates that 35 returned goods, i.e. $25.93 \%$, are delivered to their destination earlier in the second stage. In the final solution, however, this quantity increases to 70 , i.e. $51.85 \%$

TABLE III: THE INITIAL SOLUTION OF THE ILLUSTRATION EXAMPLE

\begin{tabular}{|c|c|c|c|c|c|}
\hline & $\begin{array}{l}\text { Veh. } \\
\text { ID }\end{array}$ & Routing & $\begin{array}{l}\text { Arri. } \\
\text { time } \\
(\min .)\end{array}$ & $\begin{array}{c}\text { Dept. } \\
\text { time } \\
\text { (min.) }\end{array}$ & Cost \\
\hline \multirow{6}{*}{$\begin{array}{c}1^{\text {st }} \\
\text { stag } \\
\mathrm{e}\end{array}$} & 1 & $\begin{array}{c}0-3-11-15-19-16-10- \\
0\end{array}$ & 102.68 & & \\
\hline & 2 & $0-4-18-12-13-0$ & 94.45 & & \\
\hline & 3 & $0-14-1-9-8-0$ & 123.53 & & \\
\hline & 4 & $0-20-5-2-0$ & 127.50 & & \\
\hline & 5 & $0-6-0$ & 100.99 & & \\
\hline & 6 & $0-17-7-0$ & 122.97 & 128.50 & $\begin{array}{l}6055 \\
66\end{array}$ \\
\hline \multirow{5}{*}{$\begin{array}{c}2^{\text {nd }} \\
\text { stag } \\
\mathrm{e}^{-}\end{array}$} & $1^{*}$ & $\begin{array}{c}0-46-32-33-44-47-4 \\
2-50-11^{*}-0\end{array}$ & 255.72 & & \\
\hline & 2 & $\begin{array}{c}0-31-39-40-36-28-2 \\
7-43-41-34-0\end{array}$ & 317.59 & & \\
\hline & $3^{*}$ & $\begin{array}{c}0-22-45-48-23-38-2 \\
1-49-18^{*}-0\end{array}$ & 328.21 & & \\
\hline & $4^{*}$ & $0-37-29-30-35-9^{*}-0$ & 301.49 & & \\
\hline & $5^{*}$ & $0-26-24-25-12^{*}-0$ & 322.38 & 329.21 & $\begin{array}{c}6525 . \\
96\end{array}$ \\
\hline \multirow{4}{*}{$\begin{array}{c}3^{\text {rd }} \\
\text { stag } \\
\mathrm{e}\end{array}$} & 1 & $0-3-15-19-20-0$ & 433.85 & & \\
\hline & 2 & $0-5-2-0$ & 444.69 & & \\
\hline & 3 & $0-14-1-4-0$ & 439.93 & & \\
\hline & 4 & $0-16-7-0$ & 430.25 & & $\begin{array}{c}4109 . \\
44\end{array}$ \\
\hline \multicolumn{3}{|c|}{ Total cost } & \multicolumn{3}{|c|}{16691.06} \\
\hline \multicolumn{3}{|c|}{ Total travel time } & \multicolumn{3}{|c|}{444.69} \\
\hline
\end{tabular}

Remarks: ${ }^{*}$ Earlier delivery in the second stage
TABLE IV: THE FINAL SOLUTION OF THE ILLUSTRATION EXAMPLE

\begin{tabular}{|c|c|c|c|c|c|}
\hline & $\begin{array}{l}\text { Veh } \\
\text { ID }\end{array}$ & Routing & $\begin{array}{c}\text { Arri. } \\
\text { Time } \\
\text { (min.) } \\
\end{array}$ & $\begin{array}{c}\text { Dept. } \\
\text { time } \\
\text { (min.) } \\
\end{array}$ & Cost \\
\hline \multirow{5}{*}{$\begin{array}{c}1^{\mathrm{st}} \\
\text { stag } \\
\mathrm{e}\end{array}$} & 1 & $0-15-19-6-3-0$ & 137.53 & & \\
\hline & 2 & $0-4-18-12-13-0$ & 94.45 & & \\
\hline & 3 & $0-1-9-8-14-0$ & 119.87 & & \\
\hline & 4 & $0-20-2-5-0$ & 126.48 & & \\
\hline & 5 & $0-11-17-7-16-10-0$ & 138.25 & 139.25 & $\begin{array}{l}5277.8 \\
8\end{array}$ \\
\hline \multirow{5}{*}{$\begin{array}{c}2^{\text {nd }} \\
\text { stag } \\
e\end{array}$} & $1^{*}$ & $\begin{array}{c}0-46-32-33-44-47-50 \\
-42-11^{*}-0\end{array}$ & 278.63 & & \\
\hline & $2^{*}$ & $\begin{array}{c}0-38-21-49-18^{*}-45-4 \\
8-23-3^{*}-0\end{array}$ & 332.30 & & \\
\hline & $3^{*}$ & $\begin{array}{c}0-37-29-30-35-4^{*}-9^{*}- \\
22-0\end{array}$ & 335.35 & & \\
\hline & $4^{*}$ & $0-26-25-24-12^{*}-0$ & 330.91 & & \\
\hline & $5^{*}$ & $\begin{array}{c}0-31-39-40-36-28-27 \\
-43-41-34-1^{*}-14^{*}-0\end{array}$ & 356.63 & 357.63 & $\begin{array}{c}6788.3 \\
6 \\
\end{array}$ \\
\hline \multirow{2}{*}{$\begin{array}{c}3^{\text {rd }} \\
\text { stag } \\
\mathrm{e} \\
\end{array}$} & 1 & $0-15-19-16-7-0$ & 471.13 & & \\
\hline & 2 & $0-2-5-20-0$ & 478.71 & & $\begin{array}{c}2172.9 \\
0 \\
\end{array}$ \\
\hline \multicolumn{3}{|c|}{ Total cost } & \multicolumn{3}{|c|}{14239.14} \\
\hline \multicolumn{3}{|c|}{ Total travel time } & \multicolumn{3}{|c|}{478.71} \\
\hline
\end{tabular}

Remarks: ${ }^{*}$ Earlier delivery in the second stage

TABLE V: COMPARISON OF THE INITIAL AND FINAL SOLUTIONS

\begin{tabular}{|c|c|c|c|c|}
\hline \hline & $\begin{array}{c}\text { Initial } \\
\text { solution } \\
(A)\end{array}$ & $\begin{array}{c}\text { Final } \\
\text { solution } \\
(B)\end{array}$ & $(C)$ & $\begin{array}{c}\text { Deviation } \\
\text { (mprovement } \\
(D)\end{array}$ \\
\hline \hline Total cost & 16691.06 & 14239.14 & 2451.92 & $14.69 \%$ \\
\hline Total travel time & 444.69 & 478.71 & -34.02 & $-7.65 \%$ \\
\hline \hline $\begin{array}{c}1^{\text {st }} \text { stage } \\
\text { number of route }\end{array}$ & 6 & 5 & 1 & $16.67 \%$ \\
\hline $\begin{array}{c}2^{\text {nd }} \text { stage } \\
\text { number of route }\end{array}$ & 5 & 5 & 0 & $0 \%$ \\
\hline $\begin{array}{c}3^{\text {rd }} \text { stage } \\
\text { number of route }\end{array}$ & 4 & 2 & 2 & $50 \%$ \\
\hline \hline Total number of route & 15 & 12 & 3 & $20 \%$ \\
\hline \hline
\end{tabular}

Remarks: ${ }^{*}(C)=(A)-(B) \quad{ }^{* *}(D)=(C) /(A)$

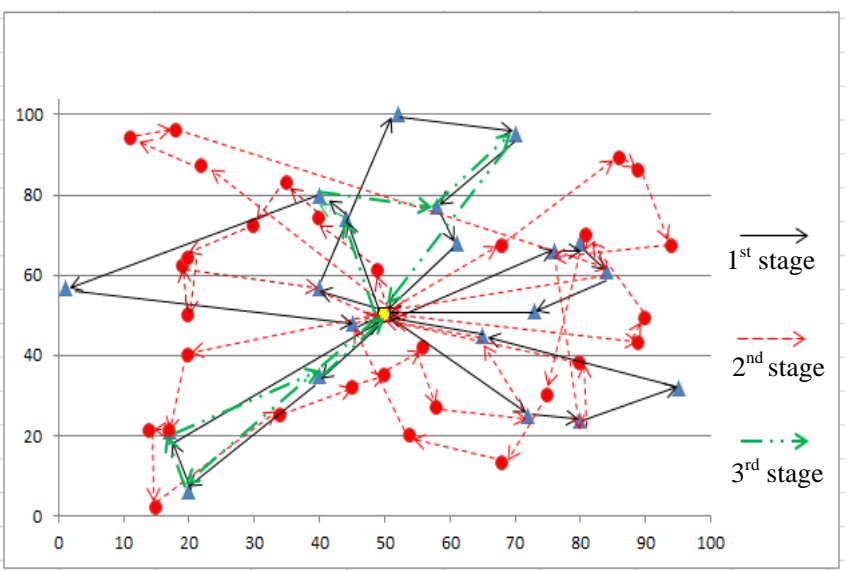

Fig. 3. Final vehicle routings for all stages

Additional experiment has been conduct to compare the system with pure independent three-stage (i.e. no earlier delivery in the second stage) and the system with some flexibility in the second stage (i.e. accept earlier delivery in the second stage) as proposed in this research. Table VI indicates the differences based on cost, time, and number of route. It is obviously that the earlier delivery policy is better than no earlier delivery policy. The total cost will further reduce up to $9.40 \%$. This phenomenon may imply that the earlier delivery policy suggested in this research is worth to implement in real-world cases. 
TABLE VI: COMPARISON OF THE EARLIER DELIVERY POLICY

\begin{tabular}{|c|c|c|c|c|}
\hline & $\begin{array}{c}\text { No } \\
\text { earlier } \\
\text { delivery } \\
\text { (A) }\end{array}$ & $\begin{array}{c}\text { Earlier } \\
\text { delivery } \\
\text { (this } \\
\text { study) } \\
(B) \\
\end{array}$ & $\begin{array}{c}\text { Deviation }{ }^{*} \\
\text { (C) }\end{array}$ & $\begin{array}{l}\text { Improvement } \\
\text { percentage } \\
\text { (D) }\end{array}$ \\
\hline Total cost & 15717.05 & 14239.14 & $\begin{array}{l}1477.91 \\
\end{array}$ & $9.40 \%$ \\
\hline $\begin{array}{c}\text { Total travel } \\
\text { time }\end{array}$ & 436.08 & 478.71 & -42.63 & $-9.78 \%$ \\
\hline $\begin{array}{c}\text { 1st stage } \\
\text { number of } \\
\text { route }\end{array}$ & 5 & 5 & 0 & $0 \%$ \\
\hline $\begin{array}{l}2^{\text {nd }} \text { stage } \\
\text { number of } \\
\text { route }\end{array}$ & 5 & 5 & 0 & $0 \%$ \\
\hline $\begin{array}{l}3^{\text {rd }} \text { stage } \\
\text { number of } \\
\text { route }\end{array}$ & 5 & 2 & 3 & $50 \%$ \\
\hline $\begin{array}{c}\text { Total number } \\
\text { of route }\end{array}$ & 15 & 12 & 3 & $20 \%$ \\
\hline
\end{tabular}

Remarks: ${ }^{*}(C)=(A)-(B) \quad{ }^{* *}(D)=(C) /(A)$

\section{CONCLUSION}

This paper proposes a new concept for vehicle transportation system. The mathematical model and the associated solution algorithm are also presented in details. Finally, the illustration example further confirms that the three-stage vehicle routing system proposed in this paper is an efficient transportation system which is worth to implement in real world cases.

\section{ACKNOWLEDGMENT}

This research is supported by the National Science Counsel, Taiwan under grant: NSC 102-2221-E-224-030.

\section{REFERENCES}

[1] U. M. Apte and S. Viswanathan, "Effective cross docking for improving distribution efficiencies," International Journal of Logistics, vol. 3, no. 3, pp. 291-302, 2000.

[2] A. B. Arabania, M. Zandiehb, and F. S. M. T. Ghomi, "Multi-objective genetic-based algorithms for a cross-docking scheduling problem," Applied Soft Computing, vol. 11, no. 8, pp. 4954-4970, 2011.
[3] Y. H. Lee, W. J. Jung, and K. M. Lee, "Vehicle routing scheduling for cross-docking in the supply chain," Computers and Industrial Engineering, vol. 51, no. 2, pp. 247-256, 2006.

[4] G. B. Dantzig and J. H. Remser, "The truck dispatching problem," Management Science, vol. 6, no. 1, pp. 80-91, 1959

[5] S. Kirkpatrick, C. D. Gelatt, and M. P. Vecchi, "Optimization by simulated annealing," Science, vol. 220, no. 4598, pp. 671-680, 1983

[6] H. F. Wang and Y. Y. Chen, "A genetic algorithm for the simultaneous delivery and pickup problems," Computers and Industrial Engineering, vol. 62 , no. 1 , pp. 84-95, 2011.

[7] C. J. Liao and Y. Lin, "Vehicle routing with cross-docking in the supply chain," Expert Systems with Applications, vol. 37, no. 10, pp. 6868-6873, 2010.

[8] G. Clarke and J. G. Wright, "Scheduling of vehicles from a central depot to a number of delivery points," Operational Research, vol. 12 , no. 4 , pp. $568-581,1964$

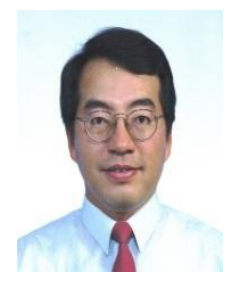

Chikong Huang was born in Taiwan on July 061958 $\mathrm{He}$ received his Bachelor degree on industrial engineering from Tunghai University, Taichung, Taiwan ROC in 1981. In 1987, he received his Master degree on industrial engineering from the University of Texas at Arlington, Arlington, Texas USA. He received his $\mathrm{Ph} . \mathrm{D}$. degree on industrial engineering from the University of Texas at Arlington, Texas USA in 1991. He is a Professor in the Department of Industrial Engineering and Management, National Yunlin University of Science \& Technology, Touliu, Yunlin, Taiwan ROC since August 1991. He has been worked as an Industrial Engineer in the Organization \& Efficiency Department of Philips Taiwan Ltd., Chupei Factory, Taiwan ROC from March 1984 to July 1986. He also worked as a Production Planner in the Production Planning Department of the Chin-Fong Machines Ltd., Changhua, Taiwan ROC from September 1983 to February 1984. Currently, his research interests are facilities planning \& design, production \& operations management, and logistic planning \& design. Prof. Huang is a member of CIIE, Taiwan ROC.

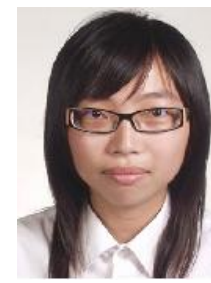

Yun-Xi Liu was born in Taiwan on August 301989. She received her Master degree on industrial engineering \& management from the National Yunlin University of Science \& Technology, Touliu, Yunlin, Taiwan ROC in 2013. She received her Bachelor degree on industrial engineering \& managemen from the National Kaohsiung University of Applied Sciences in 2011. Her research interests are logistics system design, transportation system design, and 